\title{
Plagiarism in Game Programming Competitions
}

\author{
H.J. van den Herik ${ }^{1}$, A.Plaat ${ }^{2}$, D.N.L. Levy ${ }^{3}$, and D.Dimov ${ }^{4}$ \\ TiCC, Tilburg University London, England eLaw, Leiden University
}

\begin{abstract}
On June 28, 2011 the International Computer Games Association (ICGA) disqualified and banned the program RYBKA and its programmer Vasik Rajlich from previous and future World Computer Chess Championships (WCCC). The ICGA has conducted an investigation into allegations that, in the chess program RYBKA, two other programs were plagiarized: CRAFTY and FRUIT. It was found that the allegations were true, and that the ICGA tournament rules had been broken. The investigation, the report of the investigation, and the verdict that Rajlich was guilty of the plagiarism took place in the form of a version of Crowdsourced Online Dispute Resolution (CODR). The above sentence was determined by the Board of the ICGA. This article describes, amongst other things, the background, the ICGA rules, the rules for fair play in competitions, CODR, and the future of clones. Finally, in the conclusions, the question is addressed whether the application of the ICGA rules has been fair and lawful.
\end{abstract}

\section{The ICGA Community}

The ICCA (International Computer Chess Association) was founded in 1977 and represents the Computer Chess world vis-à-vis Computer Science Organizations, such as the ACM and IFIP, and also vis-à-vis the International Chess Federation (FIDE). In 2002 the name of the Association was changed to the International Computer Games Association (ICGA), thus incorporating the International Computer Chess Association (ICCA). In the same way the ICGA also represents the Computer Games world vis-à-vis the various international federations for games other than chess.

Two of the main activities of the ICGA are: (1) to publish a quarterly ICGA Journal, and (2) to hold regular World Computer Chess Championships, Computer Olympiads, and either an Advances in Computer Games Conference (ACG) or a Conference on Computers and Games (CG).

\footnotetext{
${ }^{1}$ TiCC, Tilburg University, Tilburg, the Netherlands. Email: jaapvandenherik@gmail.com.

2 TiCC, Tilburg University, Tilburg, the Netherlands. Email: aske.plaat@gmail.com.

3 34, Courthope Road, Hampstead, London NW3 2LD, England. Email: davidlevylondon@yahoo.com.

${ }^{4}$ eLaw@Leiden, Leiden University, Leiden, the Netherlands. Email: dwdimov@abv.bg.
} 


\section{The Desire to Win}

The differences between running, swimming, cycling, chess, and computer chess are substantial. For instance, we may distinguish here three classes: sports, mind sports, and computer games. However, a similarity is that the participants in all three classes aim to win. Some participants aim to win no matter what price is paid. This attitude is debatable and in its extreme even punishable. Here, the natural question is: when does a participant cross the line? Trying to win a competition is a very human emotion. In many sports the winner is considered a hero. Each community loves their heroes and hates the people that take the heroes away from them. Recently, two international organizations, the ICGA and the USADA (United States Anti-Doping Agency) disqualified their hero after a thorough investigation. The USADA has taken Lance Armstrong away from his community and has thus removed the joy of many cycling enthusiasts from their sport. The ICGA did the same with their hero Vasik Rajlich, whose program RYBKA has won four World Computer Chess Championship titles. Being disappointed on the disqualification of a hero follows a line of reasoning which is familiar to all of us. The ordinary man does not like to pay speeding tickets given by a police officer, and do not we all, in some way, love Captain Jack Sparrow (the Caribbean pirate), who outsmarts the English governors of the law?

In summary, all sport communities where there is a desire to win are facing similar problems. The prevailing question is: how to deal with competitors who do not play according to the rules?

\section{The Relations among Research, Competition, and Commerce}

The relations among research, competition, and commerce are complex and full of contradictions. At first blush there appears to be a straightforward regulated development from research to commerce. For instance, scientific research is seen by many as an attempt to find the ultimate truth on an intricate question. Competition arises when many research groups are aiming to find the answer. Once a solution has been found it may be of interest for commerce. However, the interests of research and commerce sometimes conflict. Research and commerce meet now and then when their representatives are involved in a contest, in this article, the world computer chess championship (WCCC). Some of the ideas expressed below are adopted from Van den Herik (2001). They were then observations and expectations. Now they serve as pointers on how to deal with the consequences.

Competitiveness in research can be tough, very tough, but the focus typically is on honor, whereas in commerce the focus of competitiveness is on money and the competitors mostly search for the boundaries of what is legally permitted. Obviously university professors and businessmen live in different worlds. Now and then they meet; for instance, during conferences with product demonstrations (especially in the medical domains), or at the WCCC, where amateurs play for fun and honor while professionals compete for position and money. Obviously, a competition is needed to establish the best 
program within a given domain, and for such a contest the rules should be spelled out.

It is not always easy to ensure that amateurs and professionals are univocal on the rules to be followed. There are many obstacles, and although everybody wishes to arrive at a solution, opinions can diverge considerably. In the past an ICCA community, moderated by Bruce Moreland, had an online discussion about (1) openings books (should the book authors be classed as team-mates?), (2) multiple entrants (can the same person simultaneously be a member of two or more teams? This is particularly difficult in relation to the discussion on the opening book), (3) cloned programs (when is a program a cloned copy of an existing program?) and (4) professional interfaces (who is allowed to use ChessBase's dedicated user interface functions (cf. Van den Herik, 2001)).

In supporting software, research and commerce meet again. For instance, what is the precise position of the results of the endgame tablebases? Apparently, they are seen as solved puzzles, and therefore they are fundamentally different from the opening books. More related to the current RYBKA case is the question: how do we deal with the alpha-beta algorithm? The algorithm is not patented and all programmers may make free use of it. Over the years we have seen an impressive list of researchers. All of them have contributed in one or another way. Who should be credited for these contributions? The area is grey and full of untrodden paths, which are a challenge for the businessman and the researcher alike.

A key element in this respect is how intellectual property is treated. Scientists typically favor publication and free access to ideas, whereas commerce often chooses to protect ideas through patents or other means. In section 12 we discuss the related issue of open source licences.

\section{Fair Rules for Competition}

For the World Computer Chess Championships the tournament rules are published in the ICGA Journal (e.g., The Board of the ICGA, 2010). For the $19^{\text {th }}$ WCCC they were published on the website as well. In these rules we find Tournament Rule 2:

"Each program must be the original work of the entering developers. Programming teams whose code is derived from or including gameplaying code written by others must name all other authors, or the source of such code, in the details of their submission form. Programs which are discovered to be close derivatives of others (e.g., by playing nearly all moves the same), may be declared invalid by the Tournament Director after seeking expert advice. For this purpose a listing of all game-related code running on the system must be available on demand to the Tournament Director".

There are nine rules for each specific tournament, and eleven general rules (see The Board of the ICGA, 2010, pp. 52-55). The rules are a convergent 
set of ideas developed over more than thirty years of which the purpose is to express lawfulness and fairness. The established ideas are the norms of a community and they are valid as such for each participant who signs up for a WCCC organized by the ICGA.

Tournament Rule 2 is key to prevent plagiarism, and has been part of the Tournament Rules since the start of the World Computer Chess Championships. It should be noted that the word "derivatives" and its parenthetical clarification are an important element of this rule. In section 9 we discuss progress in machine learning, which makes the definition of "derivative" even more challenging.

Currently, the Rule is reformulated as follows (The Board of the ICGA, 2013):

"Each program must be the original work of the entering developers, possibly with the inclusion of game playing code and/or data from other sources for which the entering developers have a legal right of use. Developers whose code is derived from or includes (1) game-playing code; and/or (2) data written by others, must name (a) all the other developers of whom they are aware; and (b) the source of such code and/or data, in their tournament registration details.

Programs which are discovered to be undeclared derivatives of others may be designated invalid by the Tournament Director if he is convinced, after seeking advice if he feels that to be necessary, that the closeness of derivation is of such a level as to constitute unfair competition. A listing and an executable version of all game-related code and data running on the system must be available on demand to the Tournament Director prior to the start of and during the tournament. The Tournament Director has the right to submit the executable version of a program for testing for similarity with other known programs, and/or to submit the listing to an expert or experts of his choosing for examination, also to determine similarity. Under all circumstances the Tournament Director will take all reasonable steps to ensure that any such listing and/or executable are treated as being strictly confidential.

The entering developers must keep a copy of the source code of their entry until at least one year following the date of conclusion of the tournament, in order to be able to respond accurately to any questions about the source code that might be raised after the event by the Tournament Director."

\section{Three Previous Disqualifications}

The disqualification of RYBKA was not the first incident of disqualification for the ICGA. Disregarding minor incidents, where the disqualification took place in the submitting and accepting phase, the ICGA has experienced three 
notable disqualifications. We briefly describe them below (see also Van den Herik, 2006).

(A) In the $9^{\text {th }}$ World Microcomputer Chess Championship (Portorož, 1989), the program QUICKSTEP, was excluded from further participation after four rounds. The reason was that the program was "an unauthorized version of the MePhisto AlmeriA program" (Lang, 1989; Van den Herik and Levy, 1989).

(B) In the $11^{\text {th }}$ WCCC (Graz, 2003) the author of the program LIST refused inspection of his program code and was banned from the tournament for precisely that reason (David-Tabibi, 2003).

(C) In the $14^{\text {th }}$ WCCC (Turin, 2006) the program LION++ 1.5 was excluded from further participation after four rounds. The reason was that their work could not be characterized as original work. The casus is described in full in the tournament report by Van den Herik and Hellemons (2006). Moreover, the case is analyzed by Van den Herik (2006). The inspection of the program was conducted independently by Jonathan Schaeffer and Yngvi Björnsson. Both expert researchers came to the same conclusion: no original work. To the credit of the LION ++ 1.5 team members, we would like to state that, in their program comments, they had given credit to Fabien Letouzey, since they believed that it was necessary to do so. Up to then in Tournament Rule 2 (see section 4) it was mentioned: "... must name ... in the application details". The programmers believed that "application" meant "program" instead of "submission form". These circumstances made it possible for the ICGA to accept the team (with a different program) in a later tournament. Thus, LION ++ 1.5 was disqualified but those who entered it for the WCCC in Turin were not banned.

\section{Some Background to the RYBKA Investigation}

In 2005 the WCCC took place in Reykjavik, Iceland. Next to the (former) World Champions JUNIOR, SHREDDER, and some former runners-up, two newcomers played in the tournament. They created something of a revolution by taking the first and second places. The World Champion and its runner-up were: ZAPPA (by Anthony Cozzie) and FRUIT (by Fabien Letouzey). ZAPPA scored 10.5 out of 11 (one draw in the first round against FUTÉ which ended in the last place with a score of 0.5 out 11). Fabien Letouzey had made the trip to Reykjavik with the expectation to win the tournament, since he was convinced of the strength of his new algorithmic findings. As a fair sportsman, he accepted the status of being second (with a score of 8.5 out of 11) and disappeared more or less from the computer-chess community. He was not in commerce, he was not in competition, he was a true scientist (a researcher pur sang). After some time he decided to publish his findings (as Bob Hyatt had done with CRAFTY) under the Open Source GPL license (for details of the license system see Siewicz (2010) and Van den Herik and Siewicz (2011)).

\subsection{Open Letters}

After some time the computer-chess community was awash with rumours. The Board of the ICGA noticed the rumours but did not commence any action. 
What could they do on the basis of rumours without a clear allegation? The rumour was that RYBKA was a derivative of FRUIT. Then, on January 23, 2011, Fabien Letouzey published an open letter, and on March 1, 2011, the ICGA President, the Tournament Director, and the ICGA Board received another open letter. For historical reasons we reproduce both letters below, starting with the letter to the ICGA Board. We do neither comment on these letters nor do we explain the reference to other cases at this point.

\section{"Open letter to the ICGA about the RYBKA-FRUIT issue}

\section{March 1, 2011, 3:13 am}

Dear David Levy, Jaap van den Herik and the ICGA Board,

Recently the author of FRUIT, Fabien Letouzey, wrote an open letter to the computer chess community where he raised the concern that RYBKA 1.0 beta may be a derivative of FRUIT 2.1 in this public post.

Since then it has emerged from highly respected sources like Zach Wegner, Bob Hyatt and others that there is a lot of evidence that has been accumulated over the last few years that RYBKA 1.0 beta is a derivative of FRUIT 2.1.

Zach Wegner has presented evidence of alleged significant copied/derived FRUIT evaluations in RYBKA 1.0 beta here.

A collection of evidence of the many cases of alleged copied/derived FRUIT structure, code \& data appearing in RYBKA 1.0 beta has been put together in this PDF by Mark Watkins.

It is also worth considering that prior to RYBKA 1.0 beta, previous RYBKA versions were many hundreds of Elo points weaker than the RYBKA 1.0 beta version that suddenly emerged in public in December 2005, just a few months after the open source public release of FRUIT 2.1 under the GPL license. That same month RYBKA beta entered and won the International Paderborn Computer Chess tournament.

The evidence alleges that by using and deriving code, data and structure from FRUIT 2.1, Vasik Rajlich was able to make dramatic and huge progress with "his" program RYBKA to the detriment of his fellow competitors. In our view this has made competitions involving RYBKA grossly unfair.

As chess programmers we find this overwhelming evidence compelling. We believe RYBKA is a FRUIT derivative albeit an advanced one.

It is very likely that later RYBKA versions have derived and benefited from RYBKA 1.0 beta and hence in the circumstances our view is they should also be considered derivatives of FRUIT 2.1 until proven otherwise. 
We wish to make an official complaint to the ICGA that RYBKA is a FRUIT 2.1 derivative. Furthermore we believe it is a breach of the GPL license under which FRUIT 2.1 was released.

We believe as an unauthorized FRUIT derivative RYBKA's entry into ICGA events has been contrary to the ICGA rules and the rules of fair play.

We ask the ICGA to carefully review the evidence, assess its validity, and act accordingly.

We note that the ICGA is intending on setting up a tribunal to assess such allegations and we believe this evidence should be strongly considered in that process.

In addition, we think the ICGA should in future insist that all authors of entries to ICGA events must submit to the ICGA the same executable(s), that is taking part in the ICGA event, where they can be stored for future analysis of potential derivative claims should they arise. Each author should also make a full and clear statement as to the originality of the entry, its contributors and any acknowledgements. Should justified suspicions exist authors must be willing to submit source code on a private and confidential basis to a select group of impartial programmers to privately determine source code origin.

Co-signed by the following chess programmers, Fabien Letouzey, Zach Wegner, Mark Uniacke, Stefan Meyer-Kahlen, Ed Schröder, Don Dailey, Christophe Theron, Richard Pijl, Amir Ban, Anthony Cozzie, Tord Romstad, Ralf Schäfer, Gerd Isenberg, Johannes Zwanzger"

In the interest of history, we repeat the open letter by Fabien Letouzey, which the above letter mentions.

\section{Open letter by Fabien Letouzey}

\section{“January 23, 2011, 9:13 pm}

Hello,

Long time no see.

First, I am not back to computer chess, sorry about that. I just want to clarify a few things. Sorry if that's old but there is some misunderstanding I need to fix, and I found out only yesterday. Bear in mind that I am mostly unaware of what has happened for five years though.

First there was the Strelka case. Dann approached me with some "Strelka" source code for me to check. I had never heard of it. I assumed it was some closed-source free engine and that people wanted to know whether it was based on the FRUIT source code. 
The short answer was "no", it was not a verbatim copy of the source code. All the code had been typed (can't say "designed" though, see below) by an individual. So legally there was no issue that I knew of. It was however a whole re-write (copy with different words if you like, similar to a translation) of the algorithms. Not just an extraction of a couple of ideas as is common, and normal.

That being said, some original changes and ideas were also included in the program. So it was, as has since been stated many times in fora I suppose, a bitboard re-write of FRUIT with some personal (or otherwise) ideas. Also note that the source code Dann sent me might not be the from the 2.0 version.

Edit: I've just had a look at the 2.0 sources. On top of what I said above, there are many constant and function names that are identical to FruIT's. I remember noticing it back then as well.

Hope it helps, because my email answer to Dann was unusually short and cryptic even by my standards. And Dann, please next time make it clear when you want a public statement instead of a private opinion, thanks.

I want to point out something immediately: there was no mention of RYBKA whatsoever. Indeed I was unaware of any relation between Strelka and RYBKA, this is precisely what I learned only yesterday. I insist because it seems I have often been quoted about "not caring" about the (possible) FRUIT/RYBKA relationship, but this is not so. Strelka did not look like a problem because I assumed it was free.

Next, I was approached by Ryan (I think) and Christophe Theron about whether I could help with some "possible FRUIT code inside RYBKA" issues. I answered "yes, but how?", but did not get a reply. This did not make me really aware of a clone possibility however because I thought they were talking about some insignificant UCl-handling code or whatnot. Also this was several years after the initial RYBKA release, and I guess quite a few people had a close look at it. Apparently Chrilly did?

Now if someone could tell me a bit more about the major events last five years and the current state of affairs, l'd be much obliged.

A few things I noticed yesterday, can you confirm?

- RYBKA search info was obfuscated in some way (like displaying depth-3 or something), any pointers on details please?

- Vasik claimed that Strelka 2.0 is a clone of RYBKA 1.0 (and you know what that would imply!)

- Zach Wegner found many FRUIT ideas (and nearly identical code) in RYBKA 1.0; I think someone else did, too

- Some even stronger open-source program appeared as a decompilation of RYBKA (with own ideas, sounds familiar), what came up of looking at those? 
Any questions, now is the one time to ask.

Thanks for your attention,

Fabien Letouzey"

\subsection{Sentences and Sanctions}

Before we explore the ICGA's investigation that followed after receiving the open letter, an interesting question to consider is: what punishment could be considered appropriate by the ICGA for anyone who is found "guilty" of a cloning or derivative offence? The answer can be found in the Charter of the ICGA forum - the forum that assisted the investigation:

"[h] The ICGA shall consider the reports and recommendations of the Panel and shall at its sole discretion decide upon what action if any should be taken. The sanctions that the ICGA might take against those found guilty of cloning or creating a derivative include but are not limited to:

[i] Banning the guilty person(s) from participation in future ICGA events for any period deemed appropriate by the ICGA;

[ii] Publicizing, wheresoever it deems appropriate, the allegations and the names of those who have been investigated by the Panel and the findings of the Panel;

[iii] Recommending to other computer event organizers the exclusion of persons who have been found guilty by the Panel;

[iv] Annulling any titles that have already been awarded to programs that have since found by the Panel to have been clones or derivative programs, and demanding the return of any prize money paid to the offending programmer(s)."

\section{The Investigations and the Verdict}

The first allegations against RYBKA started in a curious way. In May 2007 a new chess program called STRELKA (Russian for "arrow") appeared on the scene. Soon there were allegations that STRELKA was a clone of RYBKA 1.0 beta, since it was found to yield identical analysis to RYBKA in a variety of different positions. However, the author of STRELKA stated that STRELKA was based on FRUIT, not on RYBKA. With the release of STRELKA 2.0 beta source code was included. Vasik Rajlich stated that the source made it "obvious" that STRELKA 2.0 beta was indeed a RYBKA 1.0 beta clone.

After the above open letter (see 6.1) had been received by the ICGA, an impending investigation was announced (cf. Levy, 2011a). Subsequently that investigation took place and is described in detail by Lefler, Hyatt, and Williamson and panel members (2011). 


\subsection{The Investigation Procedure}

The investigation was peer reviewed. It was organized by a Secretariat of three members: Robert Hyatt - (CRAFTY, CRAY BLITZ, World Computer Chess Champion in 1983 and 1986); Mark Lefler (author of Now); Harvey Williamson (member of the HIARCS team) appointed by the ICGA President and the ICGA Board. The ICGA's goal was that the investigation should be carried out by competent researchers who are members of the computer chess community. This group was initially referred to as a "forum", later a "panel", and an ICGA wiki was set up for the panelists to exchange their information. Authors of programs from past ICGA Tournaments, and other experts (their competencies to be decided by the secretariat), were deemed eligible to participate in the panel. Since the source code of RYBKA was not available, an extensive analysis of the RYBKA executable files had to be conducted. The results were to be collected and made open for inspection to all other panel members.

Chess programs consist of four parts: a graphical user interface, opening/endgame databases, the search algorithm, and the evaluation function. These last two parts can be considered to be the heart (engine) of the chess program. According to Lefler et al. (2011): "The panel investigated versions from "pre-RYBKA" 1.0 beta through RYBKA 2.3.2a, with much of the investigation concentrated on RYBKA 1.0 beta, since it was released about 6 months after the FRUIT 2.1 source code." For further details of the investigation procedure we refer to Lefler et al. (2011).

\subsection{The Actual Investigation}

The investigation found that almost the entire evaluation function of RYBKA 1.0 beta is derived from FRUIT. "This includes the formulas for calculating piecesquare tables, methods and features of evaluating piece mobility, rook/king file proximity, rook and queen on the $7^{\text {th }}$ rank, and king safety" (Wegner, 2011). We refer the reader to section 8.2 of this article where detailed information on these evaluation features is provided. Lefler, et al. (2011) quoted Zach Wegner: "From looking at the piece evaluation of both engines, we find that they are almost identical." They also quoted Mark Watkins: "I think it is safe to say that very little work was done on the RYBKA evaluation function from December 2005 to somewhere around late 2006 or early 2007 (when [Grandmaster] Kaufman was hired)."

In addition to the evaluation function the investigators examined other parts of RYBKA. They found: "Pre-RYBKA 1.6.1 contains much identical code to CRAFTY [an open source chess program], even including large blocks of code with obsolete code inside them, and code that performs tests that make no sense today (code that was left in CRAFTY by accident) [...] It is inconceivable that a second author could duplicate this code purely by chance. At least hundreds of lines of code appear to be copied [...] modules [that] are the basic "engine" including search, move ordering, and evaluation." (Lefler et al., 2011) 
The investigators noted further a sudden increase in the playing strength of RYBKA. "Early versions of RYBKA had a much lower rating. In the Chesswar 7 tournament RYBKA had a rating of approximately 2064 Elo. In a little over a year, its rating had jumped (in RYBKA 1.0 beta) to 2919 Elo, a baffling increase in playing strength. Historically, after the first year of development, programs increase at a maximum of 50-100 Elo per year. Rajlich has offered no explanation for the enormous rating increase over such a short period" (see Lefler et al., 2011).

\subsection{The Panel's Verdict}

The panel's secretariat provided two summaries of the panel's investigations, a technical summary and a general summary. We quote a relevant part of the technical summary. "RYBKA's evaluation was found to be 7.5 standard deviations from other programs, but nearly identical to FRUIT. In earlier versions of RYBKA, hundred of lines of computer code appear to be copied, indicating a continuing history of code plagiarism. Use of other people's work was not documented on the ICGA's tournament entry form as required by the ICGA rules. All panel members who expressed an opinion agree that Vasik Rajlich's RYBKA violated the ICGA Tournament Rules. Not a single panel member believed him innocent. Vasik Rajlich's claims of complete originality are contrary to the facts" (Lefler et al., 2011).

\subsection{Disqualification}

The panel verdict led to the disqualification and lifetime banning of RYBKA and its programmer from World Computer Chess Championships. In a letter dated 28 June 2011 the President of the ICGA reports on the results of the investigation (Levy, 2011b). The verdict is that RYBKA's programmer, Vasik Rajlich, has plagiarized the programs CRAFTY and FRUIT, and has violated the ICGA's tournament rules in 2006, 2007, 2008, 2009, and 2010. On all five occasions, Rajlich violated Tournament Rule 2 (see Section 4).

The letter states that "The ICGA regards Vasik Rajlich's violation of the abovementioned rule as the most serious offence that a chess programmer and ICGA member can commit with respect to his peers and to the ICGA. [...] By claiming other programmers' work as his own, and failing to comply with the abovementioned rule, Vasik Rajlich has unfairly been awarded one shared $2^{\text {nd }}-3^{\text {rd }}$ place (in 2006) and four World Computer Chess Championship titles (in 2007, 2008, 2009, and 2010)."

The letter subsequently spells out the disqualification of RYBKA, awarding the other programs the vacated titles, and the banning of Vasik Rajlich for life from competing in the World Computer Chess Championship or any other event sanctioned by the ICGA.

\section{Discussion of the Investigations}

A considerable discussion in the computer chess media arose after the ICGA published its investigation report and its decision on Vasik Rajlich's punishment. Rajlich and RYBKA have a rather wide circle of fans and so there 
were many who waded into the debate on Rajlich's side. But interestingly, there were few who claimed that he was not guilty of breaching the ICGA's Tournament Rule 2.

Most of the pro-Rajlich arguments we have seen aim their discussion at (1) the rule itself, (2) those who analyzed the RYBKA, FRUIT and CRAFTY programs in order to determine whether indeed the rule had been broken, (3) the ICGA, and (4) various individuals in the ICGA who took part in the process. We discuss these points in Subsections 8.1 to 8.4 , respectively.

The most extensive attempt to rebut the ICGA's position came from Dr. Søren Riis (2011) of the School of Electronic Engineering and Computer Science at Queen Mary University in London. Riis published a four-part article on chessbase.com in which he expressed his views in forthright terms. In response, ICGA President, David Levy (2012) published a rejoinder on chessbase.com and on chessvibes.com entitled "No Miscarriage of Justice Just Biased Reporting". In subsections 8.1 to 8.4 we include extracts of their respective discussions without explicit quotation marks.

\subsection{Interview}

To clarify the discussion Chessbase decided to hold an interview with the ICGA President, David Levy, from which we also provide relevant details (see Appendix A).To help the reader's understanding of the discussion we give a few pointers, nowadays widely accepted in the world of argumentation (Pijpers, 2013). In discussions " pro" and "con" we may distinguish four types of arguments, viz. (1) necessary and sufficient conditions for an argument to be convincing, (2) arguments that aim at a (fair) comparison, (3) causality arguments, and (4) "pragmatic" arguments (we leave the precise interpretation to the reader). Three pragmatic arguments are: inclusive we, anaphora, and claptrap (Pijpers, 2013).

\subsubsection{Discussion of the Rule}

In his four-part article on Chessbase.com about the RYBKA scandal (see www.chessbase.com/newsdetail.asp?newsid=7791 et seq.) Dr Søren Riis (2011) has tried very hard to defend Vasik Rajlich's actions that led the ICGA to find him guilty of breaking ICGA Tournament Rule 2. As a historical review of progress in computer chess Riis's article contains important and interesting information and comments. However, his thesis circles the core question and attempts to defend Rajlich by attacking the rule he was accused of breaking (see below), attacking the investigative process in various ways and attacking some of those involved in that process (see 8.2). For the main rebuttal in this point of the discussion, we cite Levy (2012).

"When a defendant is brought before a court of Law, what is in question is whether or not (s)he broke the Law and not whether the Law itself is appropriate. And so it is with the ICGA rules. In considering the RYBKA case the ICGA's task was to decide the matter on the basis of its Tournament Rule 2 , not to question the rule itself." 


\subsubsection{Comments on Søren Riis's Arguments}

Søren Riis is a moderator on the RYBKA forum. When a critic examines the details of his arguments (s)he finds that Riis's enthusiasm for RYBKA has outweighed his obedience to laws (and tournament rules) which in our opinion have to be adhered to.

A detailed and robust technical rebuttal of Riis's article by the ICGA has been published by Mark Watkins as 'A critical analysis of the four parts of Riis', and is available at http://www.chessbase.com/news/2011/watkins01.pdf

\subsubsection{Some Comments on Søren Riis's Assumptions}

Here we shall point out the irrelevance to the ICGA rules of some of his key arguments and correct some of his assumptions. We start by providing three citations.

[a] Riis states that:

"It is clear that RYBKA is an original program by any reasonable standard."

[b] Rajlich (2005) has also stated, in a CCC post of Dec 162005 : http://www.stmintz.com/ccc/index.php?id=470751

"As far as I know, RYBKA has a very original search and evaluation framework."

[c] And in an interview Rajlich (2005b) said:

http://www.superchessengine.com/vasik_rajlich.htm

"Anyway, if I really had to give a number - my wild guess is that RYBKA would be 20 rating points weaker had FRUIT not appeared."

Let us now consider the above comments in the light of the evidence. We emphasize the last of these quotations.

Ad [c] Rajlich himself has admitted earlier that "I went through the FRUIT 2.1 source code forwards and backwards and took many things". Is he here really expecting us to believe that only 20 Elo points of RYBKA's improvement were due to what he took from FRUIT, especially as this contradicts Riis's statement that, after the publication of the FRUIT source code, "everyone else" gained much more?

[d] Riis points out that:

"RYBKA maintained unbroken supremacy on the chess engine rating lists for five years. However its performance in dozens of competitive tournaments held all over the world was, if anything, even more spectacular. RYBKA did not merely win nearly every tournament it entered; it won them with a near-90\% success rate. It is difficult to 
overstate the degree of superiority that the RYBKA team exhibited in these years in chess software, mastery of hardware, and even in opening theory."

All of this paragraph is perfectly true but totally irrelevant when considering Rajlich's guilt or innocence. How would we view an Olympic athlete (or a Tour de France winner) found guilty of taking performance-enhancing drugs if he performed superbly, winning races by huge margins, breaking world records and taking gold medals? Would he be forgiven his drug-taking just because his performances were outstanding? No, of course not!

[e] Riis points out that, of the sixteen programmers who petitioned the ICGA early in 2011 to investigate RYBKA:

"many ... were in direct competition with RYBKA".

The implication here is that programmers who were competitors of Rajlich might be biased in their call for an investigation. So if one athlete reports a drug-taking rival to the athletics authorities, should the authorities discount the report because the whistle-blower is a rival? Surely not?

All of the above points are irrelevant to the core question - did Vasik Rajlich break ICGA Tournament Rule 2 or did he not? That is what the investigation panel considered, and it was on the basis of their findings and conclusions that Rajlich was sanctioned by the ICGA. Rajlich was given ample opportunity to present a defence to the allegations - the President of the ICGA (David Levy) invited him to do so before the investigation started, then again during the investigation when he sent Rajlich some of the evidence being considered, then again after the panel's report had been completed (attaching the report and all of the evidence to which it referred) but before the report was considered by the ICGA executive, and yet again after the ICGA executive had considered the report but before the ICGA Board decided on the appropriate sanctions. These prompts by Levy were sent (inter alia) on February $2^{\text {nd }}$, March $2^{\text {nd }}$, April $4^{\text {th }}$, May $13^{\text {th }}$, May $31^{\text {st }}$ and June $9^{\text {th }} 2011$. But despite being given all these opportunities to provide a serious defence to the allegations against him, over a period of five months, Rajlich consistently declined to do so. What could he reasonably expect to happen as a result?

\subsection{Discussions concerning those who analyzed the RYBKA software}

The online discussions about those who analyzed the RYBKA, FRUIT, and CRAFTY programs, in order to determine whether Tournament Rule 2 had been broken, had the nature of an indirect attack. However, the evidence the investigators put forward was overwhelming. Below we provide an example of that evidence as promised in Section 7.2.

Next consider the investigation report where it refers to Zach Wegner's analysis found at https://webspace.utexas.edu/zzw57/rtc/eval/eval.html 
"From looking at the piece evaluation of both engines, we find that they are almost identical." A partial listing of FRUIT identical terms:

Identical formulas for calculating piece-square tables for:

. pawns

. knights

. bishops

. rooks

. queens.

Highly similar formulas for piece square tables for kings.

Identical procedures for calculating king safety:

. count of pieces attacking squares around the opponent king

. adding in an attack factor based on piece type then multiplying by a weight based on attack counts

Identical simple mobility counting for:

. knights

. bishops

. rooks

. queens

Identical measurements of pawn features:

. isolation

. doubling

. open

. highly similar backward, candidate and passed pawns

Rook Evaluation:

. identical methods for $R$ on the 7th

. rooks on half and opened files

. king file proximity

Queens:

. identical $Q$ on the 7th.

Blocked Bishop and Rook terms

We repeat from Section 7.2 the summary of this part of the report: ". . nearly the entire evaluation function is derived from FRUIT. This includes the formulas for calculating piece-square tables, methods and features of evaluating piece mobility, rook king file proximity, rook and queen on the 7th rank, and king safety."

We leave it to readers to study the evidence presented in the investigation report, in Riis's article, and in Mark Watkins' (2011) rebuttal, and to decide for themselves who they believe. 


\subsection{Discussions Concerning the ICGA}

We would now like to turn to some aspects of Søren Riis's article that we regard as biased reporting.

[a] The link Riis provides to the ICGA report does not give his readers access to the important evidential documents on which the report was based. Substantial knowledge and understanding of the evidence is needed by any of Riis's readers who want to consider both sides of the arguments, and many visitors to Chessbase.com will not have seen them. The authors were rather sorry to see that Riis failed to provide such links, the more so because he did provide many links to the "defense" side.

[b] Riis states:

"It really goes without saying that the panel members voted based on the findings of the ICGA report. .."

This implies that the members of the panel were not privy to all of the evidence, and as such it is misleading. In fact the members of the panel all had access to all of the evidence documents, so they voted not only on the basis of the report but also on the basis of the evidence on which the report was based.

[c] Riis's bias is perhaps at its most telling in the following paragraph from his article:

"While no one questions the fact that the ICGA gave Rajlich ample opportunity to respond to their charges and he did not, there is much more to the matter than "we queried him and he did not respond." Rajlich was not merely queried. He was publicly accused by the head of the ICGA and publicly excoriated by a group of individuals who stirred themselves up into a crusading lynch mob. A pile of "evidence" was jubilantly thrown together based on a passionately-held predetermined conclusion of code-copying which happened to be wholly at variance with actual reality. And then Rajlich was offered the opportunity to formally respond."

There is so much to fault with this paragraph that it is difficult to know where to begin. To describe the panel of computer chess experts, many of whom are eminent academics and including a number of former world champions, as a "crusading lynch mob" is, in my view [DL], ridiculous and totally uncalled for. The members of the panel were there because they had expressed an interest in following the course of the investigation, perhaps taking some part in it, and because they were assessed as having some expertise that could be 
helpful to the discussion. To say that the evidence was "jubilantly thrown together" implies an unfair bias on behalf of those who compiled it. To go a little deeper into this particular sentence, the words "thrown together" imply that the evidence was not carefully prepared, whereas anyone reading all of the supporting documents referred to in the report would readily understand that a huge amount of time and assiduous effort had been devoted to the task of collecting and evaluating that evidence. And the words in the final sentence of this paragraph: "And then Rajlich was offered the opportunity to formally respond" imply, through the emphasis on the word "then", that the opportunity for Rajlich to defend himself came only after the investigative process had gone a long way towards its conclusion. In fact, as we have shown above, Rajlich was given several opportunities to defend himself, over a period of five months, before the report was considered by the ICGA executive. In Section 10 we provide general information on Crowdsourced Online Dispute Resolution which will place the discussion above in a general framework.

\subsection{Discussions on Individuals within the ICGA}

Below we provide three statements that were put forward by Riis (2011) and which deserve some comment.

[a] "A panel was formed. Dr. Hyatt served as panel gatekeeper and determined who was and was not allowed to participate."

Not true. The decision on who was and was not allowed to participate was taken jointly by the three members of the Secretariat and the ICGA President, after each of them had had the opportunity to make comments in favour or against particular individuals. With this statement Riis implies that the composition of the panel was somehow skewed against Vasik Rajlich, but that is also untrue. For example, Chris Whittington, a strong Rajlich supporter, asked to join and made the comment that he supposed that the ICGA President would refuse to admit him. Quite to the contrary, the President was in favour of admitting him. Unfortunately, when we asked him as part of the registration procedure to verify his email address, which no longer matched those he used for older forums, he responded using phrases such as "wasting humiliation" and "occasional little hitler"? The Secretariat felt he was unwilling to have civil dialog with others and all three of them felt he should not be a member if he was going to be rude. Then, after a brief period, he was invited to re-apply but declined to do so.

Another pro-Rajlich programmer is Ed Schröder, who was similarly welcomed to the panel when he joined. Sadly Ed then decided that he did not wish to serve and asked for his name to be removed from the panel.

Naturally Vasik Rajlich was asked to be a member of the panel with full access to all the evidence but he refused multiple requests to join. 
[b] Riis criticized Bob Hyatt in various ways, hardly surprising in view of the fact that he also criticized the rule that Rajlich broke as well as various other aspects of the investigative process. Suffice it to say that Bob Hyatt is one of the world's leading experts in the field of computer chess, has been so for some thirty years, has twice won the World Computer Chess Championship, and has contributed hugely to the field in various ways, including making his program CRAFTY open source. Who has a better understanding of computer chess and its minutiae, and who would be more appropriate as a member of the Secretariat of the Investigation Panel.

[c] Riis states:

"Not even half of the original committee of 34 voted for a guilty verdict. Was it even clear in advance how many guilty votes were needed to convict?"

There was never any compulsion on the members of the panel to take part in the vote that the ICGA conducted when the report had been completed. The purpose of the vote was to determine how the balance of opinion went amongst those panel members who did wish to vote. The result was that 16 members voted guilty and not one single member of the panel voted for a notguilty verdict. Amongst those panel members who were convinced of Rajlich's guilt was Ken Thompson, a past World Computer Chess Champion programmer, co-author of Unix, winner of the ACM Turing Award (inter alia) and arguably the most august computer scientist who has ever graced our community with his active participation.

\subsection{The ICGA President Interrogated}

Frederic Friedel of Chessbase.com subsequently carried out an interview on the subject with the ICGA President, which it published in two parts. In appendix A we reproduce some extracts for the sake of clarity. ${ }^{5}$

The extracts from Levy's rebuttal of Riis's article and from Levy's interview with Chessbase are presented to demonstrate the nature and fallacy of arguments that had appeared since the ICGA's verdict was published. We believe that they give the reader a fairly accurate picture of the ICGA's position, but also how the other side (implied by the questions) regards the matter.

\footnotetext{
${ }^{5}$ The interview has been published first on the ChessBase news page. Reproduced here by kind permission of ChessBase at www.chessbase.com.
} 


\section{A Model for Detecting Clones}

One of the key issues in Tournament Rule 2 is the question of when a program should be considered "derived." This is a difficult question, considering the advancing state of work on machine learning. One could imagine a scenario in which automated reverse-engineering of portions of a program (such as the evaluation function, or search routines) took place. Gomboc, Buro, and Marsland (2005) discuss reverse engineering of evaluations functions, and Bjornsson and Marsland (2001) report on learning search extensions. For current developments in this area we refer to DavidTabibi, Koppel, and Netanyahu (2011). In general, we nowadays may assume that a correct opponent model could be created from a competitor (if available) through machine learning. This topic has been extensively investigated by Donkers $(2005 a, b)$, Donkers et al. $(2005,2006)$ and Donkers and Spronck (2006). The main question is of course: Is such an opponent "derived" in the sense of Tournament Rule 2? For the moment, we argue for a conservative interpretation, where "derived" means direct translation or direct re-expression of code. The investigation by the ICGA has followed this interpretation. However, in the future, a more precise definition of "derived" might be in order.

A different approach for detecting clones is suggested by Ciancarini and Favini (2009) in their paper "Plagiarism detection in game-playing software". First they note that the conventional way in detecting clones is by analyzing the responses (suggested moves, lines of analysis) of two programs in a number of positions. (This is one criterion given as an example in the original ICGA rule.) However, there is a drawback to this kind of output-testing. A possibility always exists that the reason the programs came up with the same analysis was by chance, perhaps because the position has no alternatives (programs should get similar analyses of mate-in-one problems correct). Therefore, the method described by Ciancarini and Favini uses input-testing. The code of the suspected programs is analyzed using generally available similarity testing software that is used in university settings to test for plagiarism among student assignments (see, for example, http://dickgrune.com/Programs/ similarity_tester (Grune and Huntjens, 1989; Braumöller 2002; Jones 2001; Mozgovoy 2006; and Smith and Horowitz, 2009). The model suggests to compute similarity weights for different categories, such as evaluation, search, rules, and I/O. Programs that are flagged by the automatic analysis are to be further analyzed by human inspection.

The model suggests a structured method to find clones and to reduce the effort needed to find them. In doing so, its use can work as a deterrent for cheaters, and to contribute to fairness.

Previously, detecting plagiarism in tournaments took a large amount of effort by many skilled programmers, as the RYBKA case demonstrates. When the chance of getting caught is small, and the FRUITs of taking an illegal short cut are large, many programmers might be tempted. Applying automated detection systems such as the Ciancarini and Flavini model in tournaments would change these economics, and the honest programmer would benefit. 
The process leading to the ICGA's verdict that Rajlich was guilty of plagiarism, and the verdict itself, can both be seen in two different perspectives, namely lawfulness and fairness. Lawfulness refers to compliance with the formal requirements of the law. It is determined by the due process principle (see Subsection 10.1). Fairness refers to an assessment of either a decisionmaking process (procedural fairness) or the result of that process (distributive fairness), both of which are discussed in Subsection 10.2. In Subsection 10.3 we discuss some differences.

\subsection{The Due Process Principle}

The due process principle is "a set of fundamental procedural legal standards of which every citizen has an absolute right when a state or court purports to take a decision that could affect any right of that citizen" (Duhaime, 2011).

Due process is composed from two subprinciples. The first subprinciple is that no-one should be a judge in his or her own cause (nemo judex in parte sua), which means that judges should be impartial and independent. Therefore, the first subprinciple is based on the concepts of impartiality and independence. The second subprinciple is fair hearing (audi alteram partem), which means that each party should have an equal opportunity to present evidence and law. The second subprinciple is built on two concepts: (1) ensuring that each party participates in the dispute resolution process and (2) ensuring that each party can present his case and rebut the case of the opponent (Hörnle, 2009, p. 13). A graphical representation of the principle of due process can be seen in Fig.1.

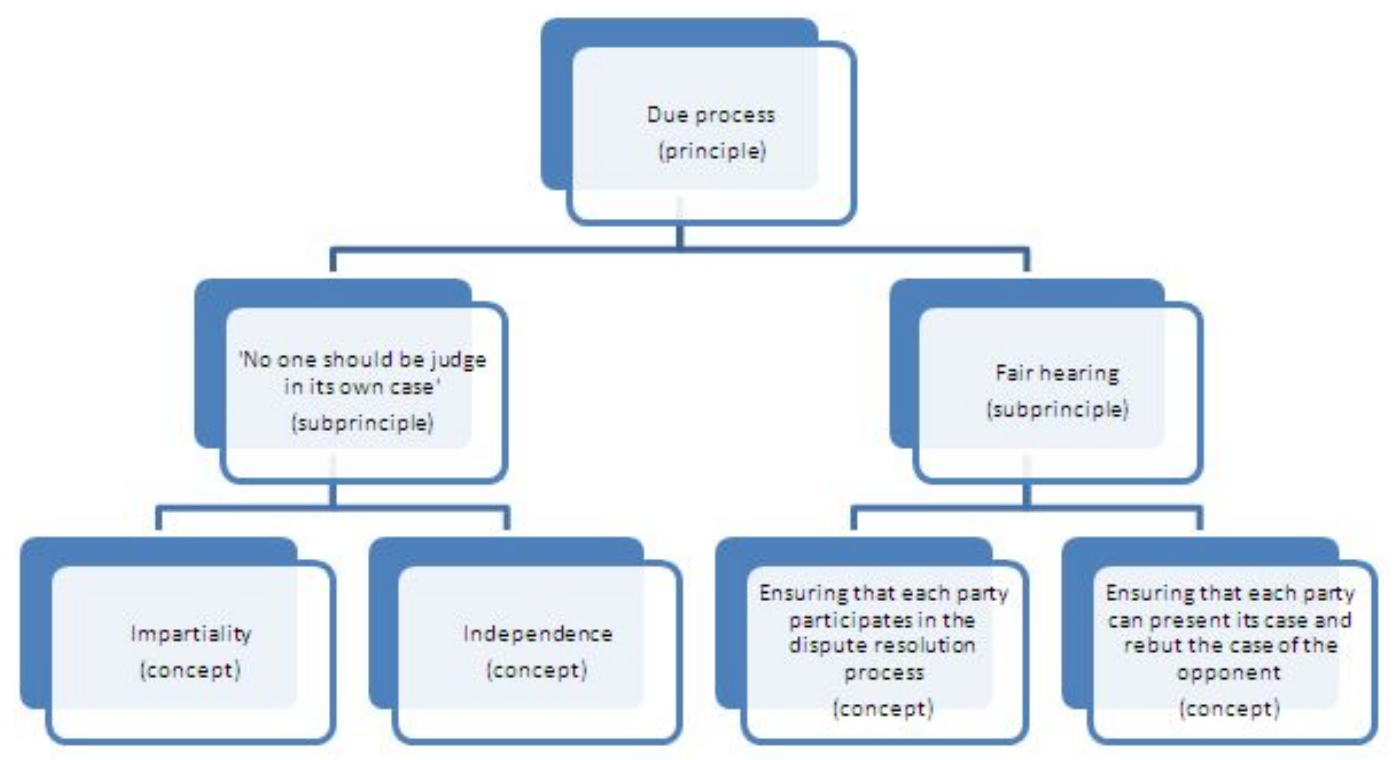

Fig. 1: The Principle of Due Process 
In relation to the first subprinciple, it should noted that the concept of "impartiality" refers to the "absence of actual bias" (Hörnle, 2009, p.113). More specifically, impartiality is related to the adjudicator/mediator's internal prejudices, prejudgment or predisposition towards some of the parties or the subject matter of the dispute. The concept of "independence" refers to there being no appearance of bias. It is a factual concept, which means an absence of an objectively ascertainable conflict of interest (Hörnle, 2009, p.114). The sub-principle that no-one should be a judge in their own case reflects equal treatment and rationality, because the task is to ensure that judges treat the "prosecuting" and "defending" parties equally, maintain an open mind, and do not take into account irrelevant considerations (Hörnle, 2009, p. 13).

\subsection{General Theories of Procedural Fairness}

The concept of procedural fairness in the context of dispute resolution is analyzed in detail by Van den Herik and Dimov (2011). They distinguish three elements of procedural fairness. Two of these elements, called "equal treatment of the parties" and "rationality", are based on the due process principle. The third element, called "effectiveness", is based on general theories of procedural fairness.

The elements of equal treatment of the parties and rationality are important elements of the concept of fairness in the process of dispute resolution. However, they are necessary but not sufficient for defining it. In this regard, Rawls (1999) acknowledges that equality cannot be achieved merely by equal treatment. He states that it is necessary to counterbalance the inequalities existing in real societies. Dworkin (1978, p.181), who wants the right of equal treatment to be understood as more than a formal protection, describes the right of equal treatment as the right "to be treated with the same respect and concern as everyone else." Habermas (1992, p.187 and p. 551) argues that equal participation is more than the formal equality we encounter in the notion of due process.

The arguments of these three authors are quite important for the conceptualization of procedural fairness because they lead to the conclusion that it is not sufficient to ensure that: (1) the parties are treated formally equally, and (2) the decisions are rational, accurate, and in accordance to the rules of law. Fairness should also redress power imbalances. Thus, in addition to the two elements of fairness - equal treatment of the parties and rationality - we should add the sub-element of counterpoise.

It should be noted that we define counterpoise as a sub-element of the concept of fairness because it, together with the sub-element of access (to be discussed below), can be grouped in a single element called effectiveness, which means that a procedure leads to a decision or solution of a dispute (Hörnle, 2009, p. 6).

The sub-element of counterpoise takes into account obstacles to effective participation, obstacles which are not inherent to the procedure, but arise from a party's inability to take part in the procedure on an equal footing (Hörnle, 
2009, p.7). This sub-element deals with pre-existing power imbalances between the parties and consists of measures to reduce them.

As mentioned earlier, there is another sub-element that should be added to the concept of fairness. This is the element of access, which means that if a dispute resolution is slow, expensive, or cannot reach a solution, the procedure is unfair. A graphical representation of the three elements and their relation to the principle of due process can be seen in Fig. 2 .

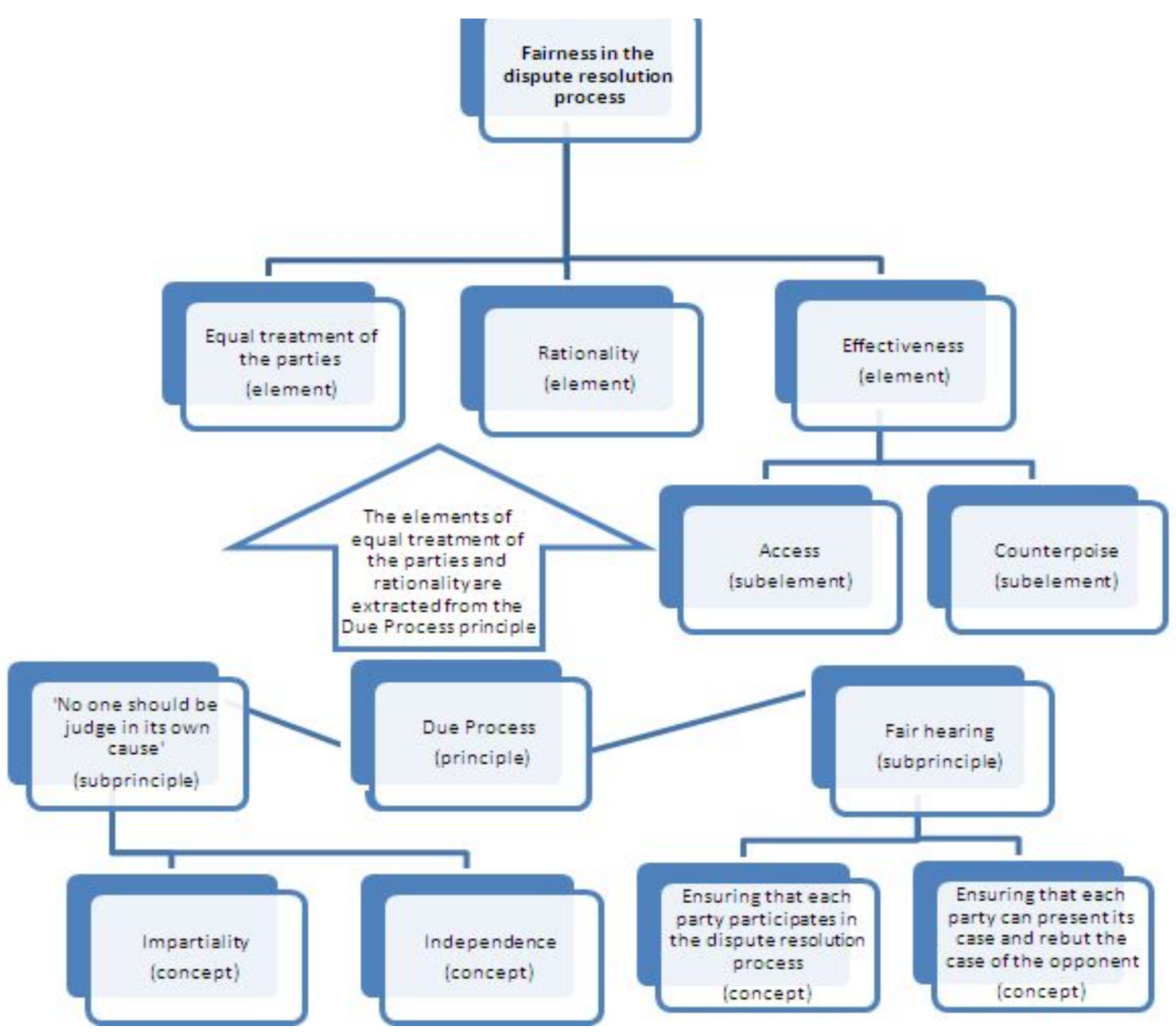

Fig.2. Relations of the Fairness Elements to the Principle of Due Process

\subsection{Some Differences}

In modern times, judging cases (dispute resolution) should be performed in a modern way (i.e., online) for two reasons: (1) speed of communication; and (2) to handle the number of complaints adequately (e.g., at eBay 60 million complaints per year are received). This modern way is called ODR (online dispute resolution). Yet, there are drawbacks for ODR (see below). As a 
consequence of these observations, and owing to various technological developments, a new type of dispute resolution was developed, called CODR (Crowdsourced Online Dispute Resolution).

There are many criteria to develop a CODR system. Here we mention six of them: (1) the mechanism used for solving disputes, (2) conditions that the crowd should satisfy in order to participate in CODR, (3) the number of members of the crowd: should it be fixed or not fixed, (4) the composition of a third neutral party in the process of dispute resolution, (5) the use of deliberations between members of the crowd, and (6) the number of members of the crowd. With the help of these six criteria, fourteen types of CODR systems can be distinguished (cf. Van den Herik and Dimov, 2011).

For a proper comparison we mention six benefits of CODR: (1) CODR can be free or provide dispute resolution at low cost, (2) CODR can resolve disputes very fast, (3) CODR does not require a presence of a paid judge, arbitrator, or mediator, (4) CODR can be designed to resolve specific types of disputes better than ODR, ADR (Alternative Dispute Resolution), or traditional litigation, (5) CODR will make the process of dispute resolution more democratic, and (6) CODR will rapidly become popular.

Moreover, there are also drawbacks. From our experience (Van den Herik and Dimov, 2011) so far, we mention two drawbacks: (1) Concerns regarding procedural fairness; and (2) difficulties in communication between the crowd and the parties.

Despite the abovementioned drawbacks we believe that CODR procedures rendering self-enforceable decisions have the potential to provide solutions that are cheap, fast, democratic, and relatively fair. Online communities need such a judicial system because the basic principle of virtual communities is that, if possible, disputes should be solved within the online community itself.

\section{The Future of Clones}

Various open questions remain regarding the future of clones vis-à-vis the World Computer Chess Championships. For the August 2013 WCCC in Yokohama, Japan, Tournament Rule 2 has been amended in an attempt to broaden the rights of the Tournament Director (see section 4).

Tournament Rule 2 has been strengthened by the announcement below which, the ICGA hopes, will make it easier to prevent undeclared derivative programs from competing in the championship. The reasoning is that at least some of the participants at the World Championship are likely to be sufficiently au fait with most of their rivals to advise the ICGA in advance of the event of attempts to register undeclared derivatives.

"Applicants in the chess events will be informed immediately following April 1 as to the whole list of chess programs for which a registration application has been received, and will be invited to inform the ICGA not later than April $15^{\text {th }}$ if they have any objections to any of the other applicants on the grounds of 
cloning or program similarity, and if so to provide a detailed reasoning and/or evidence. If any applications are received for registration after April 1, those earlier applicants of which the entries have been accepted will be similarly invited.

"Applicants for the chess events will be advised not later than April $30^{\text {th }}$ as to the list of acceptances and the amounts of travel support that will be provided for each of them (to be paid by the ICGA at the event or immediately thereafter).

"The acceptance or rejection of an entry will be determined by the ICGA President in consultation with the Tournament Director. Applicants who apply to register after April 1 will be notified as soon as possible regarding the acceptance or otherwise of their application."

The ICGA does not necessarily expect the above to be sufficient to deal with every attempt to breach Tournament Rule 2, rather it is anticipated that further changes to that rule will be made in the light of our experience in this year's and future World Championships, and in other tournaments such as those organized by the CSVN (Computer Chess Foundation in the Netherlands).

Clearly there could be considerable practical difficulties in determining, during the few days of a tournament, whether a registered program contravenes Tournament Rule 2, and even with much more time at its disposal the ICGA will need the assistance of highly experienced computer chess experts to examine any programs over which serious doubts exist. For this reason an automated tester would be of great help (see Ciancarini and Favini, 2009; see also Section 9).

12 Conclusions

Finally, we face the question as to whether the application of the ICGA rules in the RYBKA case has been both lawful and fair.

Regarding the question of lawfulness, we have submitted the details of the investigation, and its results, and the ICGA panel's verdict, to Krzysztof Siewicz, an expert in the field of "Free" (i.e., Open Source) Software, who provided us with the following analysis (see Van den Herik and Siewicz, 2011).

"FRUIT is a Free Software program. FRUIT's licence is the GNU General Public Licence, abbreviated GPL. That licence allows programmers to use FRUIT's source code in their own software, but its use is subject to certain conditions and one of those conditions is to provide recipients of copies of the software containing FRUIT code with information about the copyright in the original FRUIT program.

"If FRUIT were distributed "as is" (i.e., on its own or included as a whole within RYBKA), there is an explicit condition in the GPL to preserve copyright notices. If FRUIT were distributed in a modified form, the GPL contains a somewhat vague reference to that explicit condition, but there are also explicit conditions 
requiring the copying programmer to note all changes and to deliver, with the program containing the copied code, the source code of the original FRUIT program. In addition to the conditions mentioned in the GPL it is important to remember that copyright statutes require the assertion of moral rights, which in such cases means authorship. Usually, anyone concealing the original authorship or falsely attributing authorship is considered to be guilty of plagiarism and subject to civil or in some cases criminal sanctions.

"In my opinion the abovementioned conditions alone are sufficient to enable us to conclude that the use of FRUIT code in RYBKA, as described in the ICGA panel's reports, constitutes infringement of the GPL and most probably copyright infringement as well."

Siewicz has made the following remarks regarding the relationship between the three classes of rules that must be obeyed, namely: (1) the ICGA tournament rules; (2) the rules of the Free Software licenses; and (3) the rules of copyright laws.

"Respecting the GPL and complying with copyright restrictions do not automatically constitute compliance with the ICGA's Tournament Rule 2. It seems that this rule goes further than GPL because it allows for the possibility of declaring programs invalid when they are close derivatives of other programs, even if all authors of the copied program are mentioned and the source code of that program is made available. So the ICGA's Tournament Rule 2 is stronger than the GPL.

"Moreover, there is a very interesting issue that could be investigated more deeply, namely, identifying instances of copyright infringement other than in cases of simple copying. This is a difficult topic in other areas of copyright protection, and it is even more difficult in computer programming where there are many plagiaristic techniques available other than simple copying. Computer programs include different levels of abstraction, and it is not clear which similarities (at which level) trigger copyright infringement, and which do not.

"For example, in the ICGA's Tournament Rule 2 "playing nearly all moves the same" is given as one way to indicate that at least parts of one program are closely derived from another. But I am not sure whether such a test would always indicate a derivative in terms of the meaning of copyright law, because a similar behavior of two programs might result from similarities in their algorithms (and algorithms might, in copyright terms, constitute ideas underlying the programs), rather than from similarities between their respective source codes (which are copyright-protected expressions of ideas). In this context it must be remembered that ideas are not protected by copyright.

"Thus, it might be possible that a program is an original implementation of the same algorithm as is implemented in another program, and as a result the two programs behave in much the same way. But if that algorithm is only a non- 
copyrightable idea, the copying program's author does not breach the copyright in the copied-from program, but to comply with the ICGA's Rule 2 and participate in the ICGA's events the copying author would still need to provide the information required by Rule 2 and risk exclusion from the tournament.

"Clearly the ICGA is not obliged to base its rules on the balance struck in copyright law. Thus the ICGA is at liberty to require attribution, and it has the right to refuse to accept programs even if non-copyrightable ideas are used, thus setting a higher standard for "originality" than the one in copyright law. To summarize this difference, the ICGA rules can go further than copyright laws because these two have different purposes."

From this analysis by Siewicz we may conclude that the ICGA's treatment of the RYBKA case was lawful, because the ICGA is fully entitled to choose its own rules and to insist that participants in ICGA events abide by those rules.

Regarding the question of fairness we may conclude that the conditions for fairness expounded in sections 10.1 and 10.2 have been met in the RYBKA case, though it is of course possible to specify or define fairness in other ways. In relation to the 10.1 and 10.2 specifications of fairness we point to the lack of bias in the investigation process (Levy's responses in his ChessBase interview, see Appendix A). In relation to Hörnle's sub-principle that "each party participates in the dispute resolution process" (section 10.1), we point to part of Levy's rebuttal of Riis's articles, at the end of subsection 8.1.2, where Levy details the invitation and multiple prompts he sent to Rajlich, inviting him to respond to his accusers, and the lack of success of those missives. We argue that Rajlich participated in the process to the extent that he himself determined which was hardly at all. But that was not the fault of the ICGA. Neither would it have been the ICGA's fault if Rajlich had not responded at all to Levy's invitation. A defendant has no right to claim that he was treated unfairly because he did not participate in all or part of such a process, if his non-participation was self-determined. We therefore argue that Hörnle's subprinciples apply, and that the process was fair, although we are the first to agree that the RYBKA-case is not a straightforward one.

Thus we arrive at the end of this treatise about lawfulness, fairness, and plagiarism. Our conclusion is that the relationship between these concepts is a complex one, and we are under no illusions that the last word has been said about these issues in relation to computer chess in general and the complex RYBKA case in particular. Indeed, owing to the growing importance of software in our society we expect that many more such cases will arise. We hope that this analysis of the RYBKA case will contribute to future discussions on lawfulness, fairness, and plagiarism in Computer Chess and in other fields within the realm of computing.

\section{Acknowledgements}

Our first acknowledgement is to the many members of the computer chess community who have worked so hard in the interest of lawfulness and fairness 
of our field. We thank Frederic Friedel and ChessBase for the kind permission to publish excerpt of the interview. We acknowledge the valuable comments by the anonymous referees, which have improved the contents and presentation of this article considerably.

\section{Appendix}

\section{A. The ICGA President Interrogated}

Frederic Friedel of ChessBase.com carried out an interview on the subject with the ICGA President, which it published in two parts. We reproduce some extracts here for the sake of clarity in this appendix. ${ }^{6}$

\section{A.1 Rules and Definitions}

CHESSBASE: It would appear that Rajlich was punished not for taking code from FRUIT 2.1 verbatim, or "deriving" his program from it, but for failing to comply with our [sic] Tournament Rule 2. If for argument's sake we assume that RYBKA 1.0 Beta through 2.3.2a were clear derivatives of FRUIT 2.1, what exactly would he have had to do to comply with Tournament Rule 2?

LEVY: As we have intimated on previous occasions he should have revealed, when submitting his entries, that RYBKA was a derivative of FRUIT, in order to allow the ICGA to decide whether it should be an allowed entry.

CHESSBASE: What is the ICGA definition of "derivative"? If a programmer takes six lines of code from one of the many open source programs (CRAFTY, FRUIT, STRELKA, STOCKFISH, etc.) must this be specified in the entry form to comply with Rule 2? What if he takes twelve lines? 24? 200? Or can it be given in percentage of the entire playing code? Where is this defined in the ICGA rules or charter?

LEVY: One does not normally define things so precisely, for the same reason that the United States Constitution is open for interpretation in various places. If you paint yourself into a corner, you are stuck there, but reasonable people can come to a reasonable decision about "when is it too much to allow." And this is really an issue of functionality, rather than counting characters or lines. For example, if you copy a pawn evaluation procedure, that is copying too much. If you find a line of code that does something in a clever way you did not think of yourself, that probably would not even be noticed.

Your question implies that Rajlich might only have copied a small and insignificant amount of FRUIT, while the conclusion of the ICGA investigation was that a lot of code was copied. When considering the extent of copying no one on the panel thought that what Rajlich had done was "borderline" in a quantitative sense. The panel actually discussed how much evidence and

\footnotetext{
${ }^{6}$ This interview has been published first on the ChessBase news page. Reproduced here by kind permission of ChessBase at www.chessbase.com.
} 
which of the evidence points would be necessary and sufficient to demonstrate Rajlich's guilt, and looked closely at evaluation feature overlap because this was seen as the most notable and unarguable from the standpoint of Rule 2 (on program originality).

The essence of the case against Rajlich, as we repeatedly explain, is that when entering the World Computer Chess Championship a programming team is obliged to reveal, in their entry submission, if they have used any derived code. The ICGA can then assess, possibly after questioning the programming team and/or after examining the entrant's source code, whether or not the entry should be accepted. That will depend on the nature of what was copied, permissions received from the author of the original program, and whether another program in the same family has applied to enter the tournament.

As President I would also like to stress, as a separate issue, that a programmer should always comply with the license of the engine from which he copies the code, as well as declaring it on the ICGA entry form.

One should also mention here that, even if one were to ignore his copying of CRAFTY code, the most serious allegations of infringements by Rajlich do not start with his 2006 WCCC entry but with his December 2005 RYBKA release and its alleged copyright infringement of RYBKA. That release is not, in itself, part of the ICGA's grievance against Rajlich, since copyright infringement does not become an ICGA matter unless and until the infringing software is submitted for entry into the WCCC (see also Section 12).

\section{A.2 Letouzey's Permission}

CHESSBASE: Is it fair to say that Vasik Rajlich ruined his stellar career and his livelihood in computer chess, and got himself condemned in the world press (including CNN, Wired) as a liar, cheat, thief, plagiarist, etc. because he failed to fill out one line in the ICGA entry form correctly? [Note that filling out that line correctly would have legitimised his participation and prevented the situation that we currently have]

LEVY: That "one line" would not necessarily have solved the problem. Letouzey would also have had to give his permission as well, in order to be listed as an author. If Rajlich had declared RYBKA's FRUIT origins on the entry form and complied with the FRUIT GPL he might well have been allowed to enter with Letouzey's permission. In that case only one FRUIT-based engine would have been allowed - the one which had Letouzey's permission and his name in the entry submission.

For whatever has happened in Rajlich's life due to the ICGA's investigation and verdict, he has only himself to blame. If people do not follow rules or laws then they themselves are responsible for the consequences.

Let us now consider what might have followed if Rajlich's entry form had been filled out correctly in the first place. His entry would certainly have been 
rejected unless he had also obtained Letouzey's permission and put Letouzey's name in his entry submission. What might have happened then? Perhaps Rajlich would have become frustrated trying to write his own evaluation function, in which case he might have approached Letouzey and joined forces with him in some way, or he might have given up trying to create a world beating program and someone else might have become the world beater for the next four years (either starting from FRUIT code, with Letouzey's permission, or otherwise). Or Rajlich might have decided after all to develop his own evaluation function, in which case who knows how strong or weak RYBKA might have turned out to be?

CHESSBASE: Out of curiosity: how many other programs have listed anything or even filled out that line in the entry form in the past?

LEVY: Some programmers who enter the WCCC use the Nalimov endgame tablebases and declare as such in their entry submissions. Some programmers use openings books developed by others and similarly declare this in their entry submissions. I do not recall any entry submission that admitted to copying an evaluation function as Rajlich did (particularly in his early versions).

\section{A.3 The Panel Procedure}

CHESSBASE: How many members were there in the panel that investigated Vasik Rajlich? How many voted? Who were the members who voted and how did they vote?

LEVY: At the time of voting the panel was made up as follows: There were three members of the investigation Secretariat; four members of the ICGA board (who did not vote prior to the completion of the report), and the WCCC Tournament Director (who also did not vote prior to the completion of the report), and 34 members of the panel who were invited to vote if they wished. Here is exactly what we asked the panel members under the topic of "Opinion".

"Panel members are kindly invited to review the RYBKA-FRUIT Controversy pages and render opinions. Please answer these questions:

(a) Have you read all of the evidence linked to the RYBKA-FRUIT Controversy pages?

(b) In your opinion, did Vasik Rajlich's chess program RYBKA violate the ICGA Tournament Rules, especially rule 2 .

Sixteen panel members voted, all of whom answered "yes" to both questions. The ICGA would not divulge the names of those who voted (other than Ken Thompson) without first asking their permission and we do not intend to do so. 
CHESSBASE: Why must the names of the panel members (except one) be kept a secret? Who were the three members of the "Investigation Secretariat", and did they lead the investigation?

LEVY: We decided during the investigation process on confidentiality with respect to the names of those who voted. The Secretariat comprised: Mark Lefler, Robert Hyatt and Harvey Williamson. They administered the investigation and they wrote the report. Incidentally, I must re-iterate that the report was written after the panel members voted, whereas Søren Riis incorrectly states on Chessbase.com that "It really goes without saying that the panel members voted on the basis of the findings of the ICGA report." He should not have said that, given that it is false.

CHESSBASE: How many votes were required to pass a verdict? Was this defined anywhere before the investigation was undertaken?

LEVY: The purpose of the voting by the panel was to assess the weight of opinion of those panel members who wanted to make their opinions known, so that the secretariat could take that into account when preparing their report on the investigation and so that the ICGA office bearers could take it into account when deciding on their verdict. After the ICGA office bearers studied the report and the evidence submitted as part of the report, we voted on whether to find Rajlich innocent or guilty of breaking the ICGA's Tournament Rule 2. There was unanimous agreement on a guilty decision.

\section{A.4 The Verdict}

CHESSBASE: After the guilty vote how was the punishment determined? Where was the degree of punishment or the procedure to decide on it defined?

LEVY: The punishment was determined by the Executive Committee of the ICGA (excluding the Vice-President for Asia): David Levy, Yngvi Björnsson, Hiroyuki lida, Rémi Coulom and Jaap van den Herik, who was the Tournament Director of all the tournaments under discussion. From the outset there was no doubt about disqualification and cancellation of World Champion titles, or on the fact that a ban from participating in future ICGA events was called for. The only matter on which there was any debate was the duration of the ban. Some ICGA office bearers felt that ten years was the appropriate period, while others favoured a life ban. By a majority decision the ICGA decided to make it a life ban.

As to the procedure to decide the degree of punishment - this comes under Article III Section 1 of the ICGA Constitution (...). Section 1 states that the Executive Committee of the ICGA is charged with the administrative affairs of the association.

\section{A.5 The Panel Members}

CHESSBASE: When the investigation process against Rajlich was initiated and when the guilty verdict plus sentence was passed, the ICGA issued press 
releases and distributed them freely. The banning of Rajlich for life was reported in chess blogs and in the international media (including the New York Times and CNN). We cannot understand why the voting members of the jury who found Rajlich guilty need to be kept a strict secret (except for one, who is proudly listed). This creates the impression that some of them may have had a vested interest in the outcome of the investigation. How many panel members that voted were rival programmers who had been beaten by RYBKA in computer chess tournaments? How many voters received World Championship titles "posthumously" when RYBKA was stripped of its ICGA titles?

LEVY: We decided at the start of the process that we would not reveal the names of those who voted, so we did not know at that time who would vote and which way they would vote.

The suggestion that some of those who voted may have had a vested interest in a "guilty" verdict overlooks one very important and indisputable fact. The world of elite chess programmers is a very small one, and these are the people who are best equipped to judge the issues involved in the investigation. So Rajlich's actions were being assessed by his peers. If the ICGA had excluded from the panel anyone who is an elite chess programmer we would have been significantly diminishing the overall quality of the investigation. Remember also that I, as President of the ICGA, and the other Board members who I have listed above, were able to see not only all the evidence and all the votes of the panel, but also we were able to follow the discussion on the closed Wiki that was set up for the benefit of panel members. If any of us had seen any comments that led us to believe that any unfair bias existed within the panel's deliberations, we would have had the right and the duty to say so at the time.

Finally, on this point, I would like to add that I have always enjoyed a courteous relationship with Vasik Rajlich, and until the evidence leading to this investigation was presented to me I had absolutely nothing against him. In fact, when I was first told the rumour (as it then was) that he had used code derived from FRUIT, I did not believe it, largely because I do not regard the person who told me as a credible source. Furthermore, if I had had a choice of the verdict (in the absence of the evidence) I would very much have preferred it to have been a "Not guilty" one, as the investigation and its aftermath could do absolutely no good for the image of computer chess. The only good that has come out of the whole affair so far as I am concerned, is that programmers who are tempted in the future to break the ICGA's tournament rules in a serious way will now be less likely to do so.

CHESSBASE: Critics of the ICGA say that at least some of the members of the panel that led the investigation harboured deep personal animosity towards Vasik Rajlich and had been attacking him for years. This can be easily proved by citing many thousands of forum postings before, during and after the investigation process. Was it wise of the ICGA to rely on such members and in fact elect them to lead the investigation and draft the final report? In civil or criminal court this would have lead to an immediate mistrial. 
LEVY: The reason that Rajlich had been under attack for years is that it had been known, by some people, for years, that he had used code derived from others. The panel's Secretariat were tasked with writing the report because they were thoroughly familiar with all of the evidence revealed and discussed during the investigation. The ICGA office-bearers who considered the report could themselves judge whether or not the report represented a fair and balanced summary of the investigation and the evidence, and none of us raised any questions or objections to cast doubt on the report as an accurate summary of the evidence and the conclusions of the panel. Furthermore, it is quite typical for courts to rely on "persons with animus" regarding issues of fact (particularly ones that can be checked and verified).

\section{A.6 Background Information}

CHESSBASE: You say that the reason Vasik Rajlich had been under attack for years is that "it had been known, by some people," that he was guilty. Many of them have stood to profit from his downfall. Why was it necessary to nominate exactly those people to the jury panel that would pass judgement over him. It meant that the entire investigation and sentencing would in no way represent due process, but become an ad hoc procedure put together by the ICGA, one which one must assume could come to no other conclusion than the one it reached. Are you satisfied that justice was done?

LEVY: Yes, I am satisfied that justice was done. First I should point out that the panel was not a jury in the usual sense of the word, because its votes were always going to be regarded by the ICGA as advisory rather than a hardand-fast vote that would determine guilt or innocence. For instance, had the vote been, 9-7 in either direction, rather than 16-0 for "guilty" which it was, the ICGA office bearers would have regarded it as a strong indication that the opinion of panel members was nowhere near as clear cut as it turned out to be, and that would doubtless have affected their thinking.

We did not nominate people to the panel. We asked for people who have an interest and relevant expertise to volunteer to join the panel. The only people who were nominated were the members of the Secretariat. At most, three active competitors of Rajlich voted. None of those three panel members took an active role in the discussions so they did not influence the other members. Even if we had excluded the votes of these three, who make up fewer than one-fifth of the voting members, all the remaining voters agreed that Rajlich was guilty of violating the ICGA's Tournament Rule 2.

CHESSBASE: At most, three active competitors of Rajlich voted? This is definitely not what is being said in the computer chess forums. Are you sure of the number?

LEVY: ChessBase has always had access to the ICGA wiki since one of you (Frederic Friedel) were on the panel. If you want to disagree and say there are more than three voting active competitors, why do not you simply name them instead of mentioning the often inaccurate things posted on the forums? 
CHESSBASE: Is this a trap? In January this year programmer Ed Schröder, former ICGA world champion, posted a few names of voting members. He was reprimanded for revealing the information and immediately removed from the panel.

LEVY: Not a trap. You would name them in a question to me and if there were more than three then I would correct my answer. What Ed did was to name them publicly, which is against the terms of joining the wiki. As I look at the people who voted, I see only three active competitors. Yes, there are other chess programmers on the panel, but of the ones that voted I do not see any selling a competing product.

\section{A.7 Who is Knowledgeable and Eligible?}

CHESSBASE: You justify the procedural decision by saying that "the world of elite chess programmers is a very small one, and these are the people who are best equipped to judge the issues involved in the investigation". Really? The issue was one of copying code, which means there are literally thousands of experts available to make a judgement - in the world of general programming. Would it not have been simple to avoid the impression of cronyism or lynch justice by recusing anyone from the process who stood to gain from a guilty verdict or who otherwise had a vested interest, or harboured personal animosity towards the accused, and instead tapping in on the vast community of general computer science experts?

LEVY: There are not "literally thousands of experts" on chess programming, and it is obviously necessary for those whose opinions are being considered by the ICGA to have such expertise. In addition to computer chess experts with experience of developing chess programs the panel also included active members such as Wylie Garvin, who is a games programmer at Ubisoft, and Mark Watkins, a research fellow in the School of Mathematics and Statistics at the University of Sydney, neither of whom is from the world of competitive computer chess programmers.

CHESSBASE: We do not follow the logic: It is necessary for the experts to have chess programming expertise - but the ICGA used at least two who did not have this expertise?!

LEVY: Perhaps I did not make myself clear. There is a limited number of people with a high level of computer chess expertise, and we wanted to avail ourselves of as many of that group as we could. In addition the panel included some people (such as Mark Watkins) whose expertise is relevant even though they have not developed a competitive chess program.

Since the report was published we have seen no evidence to demonstrate that the panel and the report came to the wrong conclusions, or explaining the huge overlap of RYBKA and FRUIT in a manner that casts doubt on the guilty verdict. Additionally please remember that Rajlich was repeatedly invited to join the panel, he could also have supplied his own experts to join the panel at any time, he was given ample opportunity by way of invitation from me to 
defend himself against the allegations, and anyone with relevant expertise who believed in Rajlich's innocence was perfectly free to join the panel of their own volition, present whatever evidence and arguments they wished, and attempt to sway the other panel members towards their own point of view. None of Rajlich's supporters felt inclined to do this, which is hardly the fault of the ICGA.

\section{A.8 The Consequences}

CHESSBASE: Currently the world of chess engine programming is in a deep crisis: instead of a dozen or so highly competent teams producing new ideas and techniques, there are an increasing number of amateurs who simply reverse engineer top programs, do some optimisation and then either distribute these programs free of charge, or even start to sell them. As a result the commercial engine market has been completely destroyed and the original programmers are out of work. What has the ICGA done about this very acute problem?

LEVY: First may I say that your question is misleading, suggesting as it does that there are not "a dozen or so highly competent teams producing new ideas and techniques". What about the authors of programs such as CHIRON, FRITZ, Hiarcs, Junior, Komodo, Pandix, Shredder, SJeng, Spark, SpIKE and STOCKFISH, to name only eleven? . . . . . As to the core of your question, the commercial engine market, the ICGA is a non-commercial organisation and as such it does not concern itself with commercial matters.

\section{A.9 Additional Questions}

CHESSBASE: Is there anything you would like to add to what you have already said in this interview? A lot of readers of our news page are clamouring to ask questions. Would you be willing to answer them?

LEVY: I feel that I have answered enough questions in this interview and do not plan to take questions from your individual readers, but I would like to add to what I have already said in this interview.

The first point that I would like to emphasize very firmly relates to what I see as irrelevant comments that have been levelled at the whole ICGA investigation process by supporters of Vasik Rajlich. It is clear that the "RYBKA scandal" has aroused strong emotions on both sides of the verdict - what is unfortunate is that the strength of emotion has, in the case of many Rajlich supporters, led to comments and criticisms that are partisan to the point of lacking objectivity and/or irrelevant to the core issue. These Rajlich supporters either fail to realise and accept, or knowingly side-step, the most crucial question in all of this - Did Rajlich or did he not break the ICGA's Tournament Rule 2 when entering multiple World Computer Chess Championships? 
The pro-Rajlich lobby has been strong in its criticisms of various aspects of the investigative process, starting with the composition of the investigation panel and of the panel's secretariat, continuing through criticism of Rule 2 itself, and then complaining about the force of the sanctions imposed on Rajlich following the guilty findings of the ICGA. An analogy here would be the supporters of someone being tried in a court of law complaining about the witnesses, about the court officials, the composition of the jury, the law under which the defendant had been brought to trial, and the severity of the sentence passed on a guilty defendant. But what really matters most is the question - Did the defendant commit the offence(s) that led to the investigation or trial?

So much of the pro-Rajlich rhetoric on the forums, and some of the questions in this interview, seems to be aimed at nothing more than discrediting people. Neither the forum postings nor the questions in this interview have seriously questioned the accuracy of the evidence examined by the panel. In fact I have yet to see anything that seriously questions the accuracy of that evidence. Vasik Rajlich did indeed use code derived from FRUIT and CRAFTY, he did indeed fail to declare this with his entry applications for those ICGA tournaments, and he did indeed fail to seek and be granted permission from the authors of those programs. And with the accuracy of the evidence beyond serious question it is hardly surprising that he was found guilty by the ICGA of breaking its Tournament Rule 2 . That is the crux of the matter.

Do we think the process used during this investigation was perfect? Of course not. Could it be improved? It can and will be. But it was also not flawed in any way. The panel included several excellent motivated people, with very high levels of technical and computer chess expertise. And the investigation was carried out in a straightforward and open manner, without employing any techniques that experienced programmers could reasonably describe as being biased or incorrect. While the final outcome was painful for everyone, if the integrity of the tournaments that choose to use Rule 2 is not protected, those tournaments would become pointless and no-one would be willing to compete. One important attraction of competition is to compete with your own skills, against others using their own skills. And from the sporting perspective it is not as intellectually honest and stimulating to take bits and pieces from the work of others, as opposed to developing your skills yourself. Then, winning actually means something.

We will, for future panels, limit their size to some extent, and ensure that those who join and remain in the panel actually participate in the discussion rather than stay as spectators to the process, since that seems to have been an issue raised about the RYBKA panel. However, the 16 people with the backgrounds of those who participated in the voting within the RYBKA panel formed a remarkably expert group with more than enough expertise to fairly and thoroughly investigate potential cases of Rule 2 violation. And in fact, for the future, I do not believe that we would want a working group of more than 30 people, any more than a judge would want to put more than 30 jurors in a room together hoping for a very large majority or a unanimous decision. Some might argue that even the 16 or more who we had actively participating in the 
RYBKA panel is probably pushing the limit a bit, although in this case there were no disagreements at all. The very fact that the 16 who voted generally had a much higher level of understanding of computer chess programming than almost all of those Rajlich supporters whose voices have been heard in the forums, adds significant weight to the ICGA's confidence in the investigation process and in the panel's report. And the fact that those 16 people voted unanimously for guilty verdicts speaks for itself.

Many of the Rajlich supporters posting on the forums have supported the argument about "a new paradigm created by open-source programs", without realising that that concept is just nonsense. Most people still know that copying the work of others and claiming it to be original is wrong, just as it has always been.

\section{A.10 Two Sides}

The above extracts from Levy's rebuttal of Riis's article and from Levy's interview with Chessbase are presented here to demonstrate the nature and fallacy of arguments that had appeared since the ICGA's verdict was published. We believe that they give the reader a fairly accurate picture of how each side of the debate regards the matter.

\section{References}

Y. Björnsson and T. A. Marsland (2001). Learning Search Control in Adversary Games. Proceedings of the Ninth International Advances in Computer Games Conference (ACG'99), Paderborn, Germany, June 16-18, pp. 157-174.

B. Braumöller, B. Gaines (2002). Actions do speak louder than words: deterring plagiarism with the use of plagiarism-detection software, Political Science and Politics 34 (4) pp. 835-839.

P. Ciancarini, G.P. Favini (2009). Detecting clones in game-playing software. ScienceDirect - Entertainment Computing, Volume 1, Issue 1, January 2009, Pages 9-15.

O. David-Tabibi (2003). The $11^{\text {th }}$ World Computer Chess Championship. ICGA Journal, Vol. 28, No. 4, pp. 252-259, esp. 257.

O. David-Tabibi, M. Koppel, N.S. Netanyahu (2011). Expert-driven genetic algorithms for simulating evaluation functions. Genetic Programming and Evolvable Machines 12(1): 5-22.

H.H.L.M. Donkers (2005a) Tree Search in Two-Player Games - Using Bounded Rationality to Prune. Joint Conference on Information Sciences, Special Session on Computer Games. Salt Lake City, Utah, July 21-26, 2005. CD-ROM, ISBN 09707890-3-3

H.H.L.M. Donkers (2005b). Nosce Hostem, Searching with Opponent Models. Ph.D. Thesis, Maastricht University. Datawyse b.v., Maastricht, The Netherlands. 
H.H.L.M. Donkers, J.W.H.M. Uiterwijk, H.J. van den Herik (2005). Selecting Evaluation Functions in Opponent-Model Search, Theoretical Computer Science, 349 (2) 245-267.

H.H.L.M. Donkers, H.J. van den Herik, and J.W.H.M. Uiterwijk (2006). Similarity Pruning in PrOM Search. 11th Advances in Computer Games Conference (ACG 11), (H.J. van den Herik, S-C. Hsu, T-sh. Hsu, and H.H.L.M. Donkers), LNCS 4250, Springer-Verlag, Berlin, pp. 57-72.

H.H.L.M Donkers and P. Spronck (2006). Preferenced-Based Player Modelling. In (Steve Rabin, editor) Al Game Programming Wisdom 3, Charles River Media, Boston, MS, pp. 647-660.

Duhaime (2011). Legal Dictionary, http://www.duhaime.org/LegalDictionary/ D/DueProcess.aspx (Last checked on 06 February 2013)

R. Dworkin (1978). Taking Rights Seriously. Harvard University Press.

D. Gomboc, M. Buro, T.A. Marsland (2005). Tuning evaluation functions by maximizing concordance. Theor. Comput. Sci. Vol. 349, No. 2, pp. 202-229.

D. Grune and M. Huntjens (1989). Detecting copied submissions in computer science workshops, Technical Report, Informatica Faculteit Wiskunde \& Informatica, Vrije Universiteit, Amsterdam.

J. Habermas (1992). Faktizität und Geltung. Suhrkamp.

H.J. van den Herik (2001). Science, Competition, and Business. ICGA Journal, Vol. 24, No. 4, pp. 201-201.

H.J. van den Herik (2006). The Interpretation of Rules. Editorial. ICGA Journal, Vol. 29, No. 2, pp. 53-54.

H.J. van den Herik and D. Levy (1989). Disqualified at Portorož. ICGA Journal, Vol. 12, No. 12, pp. 233-234.

H.J. van den Herik and J.W. Hellemons (2006). The $14^{\text {th }}$ WCCC. ICGA Journal, Vol. 29, No. 2, pp. 83-94.

H.J. van den Herik and D. Dimov (2011). Towards Crowdsourced Online Dispute Resolution, Law Across Nations: Governance, Policy \& Statutes, Kierkegaard, S. (Ed.), Kierkegaard, P. (Assoc. Ed.), International Association of IT Lawyers (IAITL), pp. $244-257$. Available at: http://papers.ssrn.com/sol3/papers.cfm? abstract_id=1933392.

H.J. van den Herik and K. Siewicz (2011). Open Source has a Price. ICGA Journal, Vol. 34, No. 2, pp. 65-66.

J. Hörnle (2009). Cross-Border Internet Dispute Resolution. Cambridge University Press.

E. Jones (2001). Metrics based plagiarism monitoring, in: Proceedings of the Sixth Annual CCSC Northeastern Conference on the Journal of Computing in Small Colleges, Consortium for Computing Sciences in Colleges, USA, pp. 253-261. 
R. Lang (1989). The Ninth World Microcomputer Chess Championship. ICGA Journal, Vol. 12, No. 4, pp. 232-233.

M. Lefler, R. Hyatt, H. Williamson, and panel members (2011). RYBKA investigation and summary of findings for the ICGA. ICGA Journal Vol. 34, No. 2, pp. 120-127.

D. Levy (2011a). Attack of the Clones. ICGA Journal, Vol. 34, No. 1, pp. 3-6, see also "Attack of the Clones". chessvibes.com.

http://www.chessvibes.com/reports/attack-of-the-clones.

D. Levy (2011b). RYBKA disqualified and banned from world computer-chess championships. ICGA Journal, Vol. 34, No. 2, pp. 67-68.

D. Levy (2012). No Miscariage of Justice-Just Biased Reporting.

harveywilliamson.com. pp. 10.

http://www.harveywilliamson.com/ICGA/DL_Rebuttal_to_Riis_article.January7th2012 .doc. Retrieved January 09, 2012.

M. Mozgovoy (2006). Desktop tools for offline plagiarism detection in computer programs, Informatics in Education 5 (1) 97-112.

K. Pijpers (2013). Overtuigend Argumenteren. Workshop LUF Dies Natalis 2013, Leiden University, Leiden, the Netherlands.

V. Rajlich (2005a). http:/www.stmintz.com/ccc/index.php?id=470751.

V. Rajlich (2005b). Superchessengine.com. 2005-12-20.

http://www.superchessengine.com/vasik_rajlich.htm. Retrieved 2011-01-02.

J. Rawls (1999). A Theory of Justice. Oxford University Press.

S. Riis (2011). (January 05, 2012). "A Gross Miscarriage of Justice in Computer Chess". ChessBase.com. pp. 31. http://www.chessbase.com/news/2011/riis01.pdf. Retrieved January 05, 2012.

K. Siewicz (2010). Towards an Improved Regulatory Framework of Free Software, Protecting user freedoms in a world of software communities and eGovernments. $\mathrm{PhD}$ Thesis, Leiden University.

R. Smith and S. Horwitz (2009). Detecting and measuring similarity in code clones, in: Proceedings of the Third International Workshop on Software Clones, Kaiserlautern, Germany, 2009, dx.doi.org/10.1109/CSMR.2009.45.

The Board of the ICGA (2010). Rules for the $19^{\text {th }}$ WCCC, ICGA Journal, Vol. 33 , No. 1, p. 52-55.

The Board of the ICGA (2013) Rules for the $20^{\text {th }}$ World Computer Chess Championships, ICGA Journal, Vol. 36, No. 1. pp. 57-61. 
M. Watkins (2011). A critical analysis of the four parts of Riis at http://www.chessbase.com/news/2011/watkins01.pdf.

Z. Wegner (2011). https://webspace.utexas.edu/zzw57/rtc/eval/eval.html.

\section{Additional References}

For the benefit of the interested reader we include as background material a list of references to the RYBKA discussion. These discussions are not explicitly referenced in the text, but are implicit in much of the controversy.

1. RYBKA wins WCCC 2008. Available from: <http://www.grappa.univlille3.fr/icga/game.php?id=1>.

2. RYBKA vs. StRELKA. Available from: <http://RYBKAforum.net/cgibin/RYBKAforum/topic_show.pl?pid=39198\#pid39198>.

3. RYBKA vs. FRUIT. Available from: $<$ http://www.talkchess.com/forum/viewtopic.php?topic_view=threads $\& p=2220$ $65 \& \mathrm{t}=24047>$.

4. Plagiarism in computer Go. Available from: <http://www.msoworld.com/mindzine/news/scandals/scandal0400.html>.

5. Rules of WCCC 2008. Available from: <http://www.grappa.univlille3.fr/icga/event_info.php?id=20>.

6. http://en.wikipedia.org/wiki/RYBKA

7. Technical rebuttal of the Riis articles: http://chessbase.com/news/2011/watkins01.pdf

8. http://www.spiegel.de/netzwelt/gadgets/schach-software-RYBKAprogrammierer-vermuten-intelligenzklau-a-748616.html

9. http://www.chessvibes.com/reports/attack-of-the-clones

10. http://www.chessvibes.com/reports/programmers-write-open-letter-aboutRYBKA-FRUIT-issue/

11. http://www.chessvibes.com/reports/controversy-over-RYBKAs-disqualificationand-ban-update

12. http://www.chessvibes.com/reports/RYBKA-disqualified-and-banned-fromworld-computer-chess-championships/

13. http://www.metro.co.uk/news/867998-computer-chess-reels-from-biggestsporting-scandal-since-ben-johnson

14. "RYBKA 4 Release Notes". RYBKAforum.net. http://RYBKAforum.net/cgibin/RYBKAforum/topic_show.pl?tid=17010. Retrieved 2011-01-02.

15. "CCRL 40/40 - Pure list". July 3, 2010. http://www.computerchess.org.uk/ccrl/4040/rating_list_pure.html. Retrieved 2010-07-12.

16. "CEGT 40/20". Chess Engines Grand Tournament. July 11, 2010. http://www.husvankempen.de/nunn/40_40\%20Rating\%20List/40_40\%20All\% 20Versions/rangliste.html. Retrieved 2010-07-12. 
17. "The SSDF Rating List". Swedish Chess Computer Association. March 21, 2010. http://ssdf.bosjo.net/list.htm. Retrieved 2010-07-12.

18. "Bayesian Elo Ratinglist WBEC Ridderkerk edition 1 - 16". September 22, 2009. http://wbec-ridderkerk.nl/html/BayesianElo_ed16.htm. Retrieved 201004-27.

19. IPON; Ponder ON Rating list

20. Doggers, Peter. "RYBKA disqualified and banned from World Computer Chess Championships". Chess Vibes. http://www.chessvibes.com/reports/RYBKAdisqualified-and-banned-from-world-computer-chess-championships/.

Retrieved 29 June 2011.

21. "RYBKA source code". RYBKAforum.net. http://RYBKAforum.net/cgibin/RYBKAforum/topic_show.pl?pid=20132\#pid20132. Retrieved 2011-01-02.

22. http://RYBKAforum.net/cgibin/RYBKAforum/topic_show.pl?pid=19588\#pid19588

23. http://RYBKAforum.net/cgibin/RYBKAforum/topic_show.pl?pid=17961\#pid17961

24."RYBKA @ Amsterdam 15th WCCC". RYBKAforum.net. http://RYBKAforum.net/cgibin/RYBKAforum/topic_show.pl?pid=15090\#pid15090. Retrieved 2011-01-02.

25. Richey, Volker. "CCT6 Results". http://www.vrichey.de/cct6/index_table.htm. Retrieved 22 Feb 2011.

26. "Chess War V D Results". http://www.openaurec.com/chesswar/Chesswar005/Chesswar005DSt.htm. Retrieved 22 Feb 2011.

27. "Swiss System Season 3 Top 200 results". http://americanfoot.free.fr/echecs/suisse/sui/sui3top200-9.htm. Retrieved 22 Feb 2011.

28. "Chess War VI D Results". http://www.openaurec.com/chesswar/Chesswar006/Chesswar006DSt.htm.

29. "Chess War VII C Results". http://www.openaurec.com/chesswar/Chesswar007/Chesswar007CSt.htm.

30. "AEGT Results". http://iggor.110mb.com/aegt.php.

31. "Computerschaak - ONK 2007". Csvn.nl. http://www.csvn.nl/index.php?option=com_content\&task=view\&id=282\&Itemid =46. Retrieved 2011-01-02.

32. "RYBKA Open Nederlands Kampioen 2008". Csvn.nl. 2008-11-16. http://www.csvn.nl/index.php?option=com_content\&task=view\&id=352\&Itemid =28\&lang=en. Retrieved 2011-01-02.

33. CCT11 Final Scoreboard ${ }^{\text {[dead link] }}$

34. "7th World Computer Chess Championship". Grappa.univ-lille3.fr. http://www.grappa.univ-lille3.fr/icga/tournament.php?id=192. Retrieved 201101-02. 
35. van Reem, Eric (2010-05-31). "RYBKA wins ICT10 in Leiden". ChessBase. http://www.chessbase.com/newsdetail.asp?newsid=6381. Retrieved 31 May 2010.

36. "RYBKA vs Ehlvest II - information center". RYBKAforum.net. http://RYBKAforum.net/cgi-bin/RYBKAforum/topic_show.pl?tid=1614. Retrieved 2011-01-02.

37. "RYBKA vs Dzindzichashvili - information center". RYBKAforum.net. http://RYBKAforum.net/cgi-bin/RYBKAforum/topic_show.pl?tid=3363. Retrieved 2011-01-02.

38. The Milov vs. RyBKA Handicap Match, Chessbase, September 24, 2008

39. "RYBKA (Computer) vs Zappa (Computer) (2007) "Mothers of Invention"'. Chessgames.com.

http://www.chessgames.com/perl/chessgame?gid=1473884. Retrieved 201101-02.

40. "PGNs of game 3 and 4 with RYBKA evaluation, Zappa won both".

RYBKAforum.net. http://RYBKAforum.net/cgi-

bin/RYBKAforum/topic_show.pl?tid=2235. Retrieved 2011-01-02.

41. "Challenge To FIDE".

http://www.RYBKAchess.com/docs/ChallengeToFIDE.htm.

42. "A Lost Opportunity". http://www.chessninja.com/download/RYBKA-juniornomatch-levy.pdf.

43. "Zappa vs RYBKA, 2007". http://www.chessgames.com/perl/chessgame?gid=1474494.

44. "RYBKA 3 Release Notes". August 6, 2008. http://RYBKAchess.com/index.php?auswahl=Release+notes. Retrieved 200808-07.

45. Chessvine Article, "A 'Little Fish' (RYBKA) in Corporate Waters"[dead link]

46. RYBKA Aquarium: Interview with the Developers ${ }^{\text {[dead link] }}$

47. "RYBKA in Chess Classic Mainz 2007, Chess 960". RYBKAforum.net. http://RYBKAforum.net/cgibin/RYBKAforum/topic_show.pl?pid=14910\#pid14910. Retrieved 2011-01-02.

48. "CCM7 - 3. Livingston Chess960 Computer-Weltmeisterschaft". Chess Tigers. http://chesstigers.de/ccm7/computer_wm.php?lang=0\&kat=6\&subkat=1. Retrieved 2007-08-22.

49. "CEGT". Husvankempen.de. http://www.husvankempen.de/nunn/40_40\%20Rating\%20List/40_40\%20All\% 20Versions/rangliste.html. Retrieved 2011-01-02.

50. "RYBKA 4 update". RYBKAforum.net. http://RYBKAforum.net/cgibin/RYBKAforum/topic_show.pl?tid=16262. Retrieved 2011-01-02.

51. http://chessok.com/?p=512

52. "(Experimental) 64-bit RYBKA on Linux". RYBKAforum.net. http://RYBKAforum.net/cgibin/RYBKAforum/topic_show.pl?pid=18932\#pid18932. Retrieved 2011-01-02. 
53. "I want know if RYBKA will be developed for pocketpc". RYBKAforum.net. http://RYBKAforum.net/cgibin/RYBKAforum/topic_show.pl?pid=18095\#pid18095. Retrieved 2011-01-02.

54. "RYBKA Cluster for the elite chess player". RYBKAchess.com. http://www.RYBKAchess.com/Cluster. Retrieved 2011-02-01.

55. "STRELKA 1.0 x32:RYBKA clone?". RYBKAforum.net. http://RYBKAforum.net/cgibin/RYBKAforum/topic_show.pl?tid=939. Retrieved 2011-01-02.

56. "STRELKA = RYBKA 1.0". RYBKAforum.net. http://RYBKAforum.net/cgibin/RYBKAforum/topic_show.pl?pid=18905. Retrieved 2011-01-02.

57. "osipovs arguments about STRELKA". RYBKAforum.net. http://RYBKAforum.net/cgi-bin/RYBKAforum/topic_show.pl?tid=3015. Retrieved 2011-01-02.

58. "STRELKA 2.0". RYBKAforum.net. http://RYBKAforum.net/cgibin/RYBKAforum/topic_show.pl?pid=39198\#pid39198. Retrieved 2011-01-02.

59. http://www.playwitharena.com/directory/reviews.htm

60. "Open letter of Fabien Letouzey". talkchess.com. http://talkchess.com/forum/viewtopic.php?topic_view=threads $\& p=389683 \& \mathrm{t}=3$ 7762. Retrieved 2011-02-01.

61. "IPPOLIT - home". Ippolit.wikispaces.com. 2010-12-26. http://ippolit.wikispaces.com/. Retrieved 2011-01-02.

62. http://www.chesslogik.com/FireBird.htm ${ }^{\text {[dead link] }}$

63. http://www.talkchess.com/forum/viewtopic.php?t=7

64. "ChessVibes News". Chessvibes.com. http://www.chessvibes.com/reports/chess-engine-controversy/\#more-23466. Retrieved 2011-01-02.

65. "Official statement on Ippolit". RYBKAforum.net. 2009-10-21. http://RYBKAforum.net/cgi-bin/RYBKAforum/topic_show.pl?tid=12995. Retrieved 2011-01-02.

66. http://ippolit.wikispaces.com/IPPOLIT.C

67. http://talkchess.com/forum/viewtopic.php?t=37381

68. "RYBKA has same 99999 bug as CRAFTY". Open-Chess.Org. http://www.openchess.org/viewtopic. $p h p ? f=3 \& t=1175 \& p=10967 \# p 10967$.

69. "Is RYBKA a derivative of FRUIT?". RYBKAforum.net. http://RYBKAforum.net/cgibin/RYBKAforum/topic_show.pl?pid=19118\#pid19118. Retrieved 2011-01-02.

70. "Evaluation". Webspace.utexas.edu. https://webspace.utexas.edu/zzw57/rtc/eval/eval.html. Retrieved 2011-01-02.

71. "RYBKA Chess Community Forum". RYBKAforum.net. http://RYBKAforum.net/cgi-bin/RYBKAforum/topic_show.pl?pid=205163;hl=. Retrieved 2011-01-02.

72. "PDF for Founding statutes". http://ticc.uvt.nl/icga/data/www.icga.wikispaces.com.pdf.

73. http://www.chessvibes.com/reports/programmers-write-open-letter-aboutRYBKA-FRUIT-issue/

74. ICGA Investigation Documents 
75. Hurriyet Daily News: 'Cheating' computer disqualified from chess tournament

76. Chess Vibes: RYBKA disqualified and banned from World Computer Chess Championships

77. Washington Times: Computer chess champ stripped of its four titles

78. Tech World: World's best chess program loses titles in plagiarism row

79. Extreme Tech: RYBKA, the world's best chess engine, outlawed and disqualified

80. "Another Conversation with Vasik Rajlich" By Nelson Hernandez (on RYBKA chess)

81. Watkins, Mark (January 09, 2012). "A Critical Analysis Of The Four Parts Of Riis". harveywilliamson.com. pp. 16.

http://harveywilliamson.com/ICGA/Riis3.pdf. Retrieved January 09, 2012.

82. FIDE: Ethics Commission Decisions (2012)

83. Chessbase article: ICGA/RYBKA controversy: An interview with David Levy (Part 1)

84. ChessBase article: ICGA/RYBKA controversy: An interview with David Levy (Part 2)

85. Clone Engine List. Available from: <http://computerchess.org/doku.php?id=computer_chess:wiki:lists:clone_engine_list>.

86. Post by Ed Schroeder, author of Rebel: http://rybkaforum.net/cgibin/rybkaforum/topic_show.pl?tid=26435 